2. McCracken, C. W., Dubin, M. "Dust Bombardment on the Lunar Surface" NASA Tiv D-2100, 1963; also in Lunar Surface Layer, Materials and Characteristics. Eds. J. W. Salisbury and P. E. Glaser, Academic Press, New York, pp. I79-214, 1964.

3. Thornbury, W. D. Principles of Geomorphology. Wiley, New York and London, pp. 32 I ff, I954.

4. Kuiper, G. P. "The Exploration of the Moon", Vistas in Astronautics. Pergamon Press, vol. 2, section C, p. 303 , 1959 .

5. Strom, R. G. Comm. Lunar and Planetary Laboratory, no. 39, I964.

6. O'Keefe, J. A. Science, 146, 5I4-5I5, I964.

\title{
6. INTERPRETATION OF THE SMALL CRATERS OF THE MOON'S SURFACE REVEALED BY RANGER VII
}

\section{E. M. Shoemaker}

(U.S. Geological Survey, Flagstaff, Ariz., U.S.A.)

The small topographic features revealed by the Ranger VII photographs of Mare Cognitum are almost all craters. Craters thus are not only the dominant large topographic features on the Moon but also the dominant small topographic form revealed by Ranger VII. The newly observed craters are of many shapes. Some may be recognized as belonging to certain classes of craters observed through the telescope, but many less than $300 \mathrm{~m}$ across cannot be classified by shape alone in the categories previously recognized by telescopic observations.

\section{Shapes of craters}

Two basic types of craters well known from telescopic observations can be readily identified in the Ranger photographs: ( 1 ) primary craters and (2) secondary craters.* These types are defined on the basis of morphology and distribution. Small telescopically observable primary craters are typically uniform in shape. They are nearly circular and have a distinct, smooth, raised rim, generally of nearly uniform height. The inner walls are smooth, uniform, steep, and slightly concave upward. Typical slopes of the wall near the rim crest are greater than $35^{\circ}$ and, near the foot, about $25^{\circ}$. In primary craters larger than about $7 \mathrm{~km}$ in diameter, the steep wall terminates against a relatively smooth, level, circular floor. The diameter of the floor diminishes with size and is very small or absent in primary craters less than $7 \mathrm{~km}$ across; the walls thus extend to the center or almost to the center of these small craters. As Kuiper has remarked (r), these remarkably uniform craters look as though they had been turned out on a lathe. They are scattered across the maria and other parts of the Moon without apparent control by other surface features. Some of them are surrounded by a bright halo, or a system of rays; others are not.

With increased diameter, the primary craters are less regular in form. At $25 \mathrm{~km}$ diameter, some irregular hummocks are found in the rim, terraces occur on the crater walls, and irregularities begin to appear on the floor. At 50 or $60 \mathrm{~km}$ diameter, the rims are typically rugged and hummocky, the rim crest is uneven and commonly roughly hexagonal in plan, the walls are terraced, and the floor is marked by scattered hills and one or more prominent irregular peaks near the center of the crater. A swarm of small craters, which are barely resolvable through the telescope, surrounds a primary crater of this size.

* Other classes of craters known from telescopic observations, such as chain craters and craters at the summits of domes, are apparently not represented in the high-resolution Ranger VII photographs and will not be discussed in this report. 
These small craters, whose forms can be distinguished only in the swarms that occur around very large primaries, are called secondary craters. Several thousand of them can be observed in the swarms that surround large primary craters such as Tycho (Fig. I). The greatest density of secondary craters in the swarm occurs about one crater diameter from the rim crest of the primary. At greater distances, the secondary craters are clustered within rays or within arcuate and loopshaped bands extending outward, in some cases hundreds of miles, from the primary crater.

The secondary craters that can be photographed with Earth-based telescopes (generally $\mathrm{I} \mathrm{km}$ across or larger) are in most cases readily distinguishable from very small primary craters. The secondary craters are typically elongate, are generally shallower than primaries of corresponding size, and in most cases have low irregular rims, or no rims at all. Many elongate secondaries, when observed through the telescope under favorable conditions, are seen to be composite, consisting of several small craters strung end to end or merged together. The secondary craters are found around primary craters with rays and also around those without

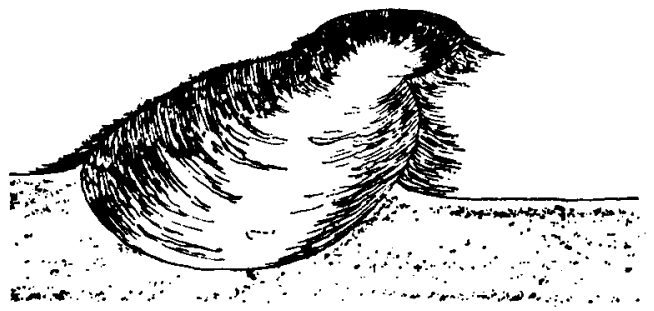

FIG. 2. Diagrammatic sketch of a composite secondary crater of Copernican age. (Copernican secondary craters that can be resolved with Earth-based telescopes generally have distinct raised rims and may show internal cusps. Based on telescopic observations of M. H. Carr.)

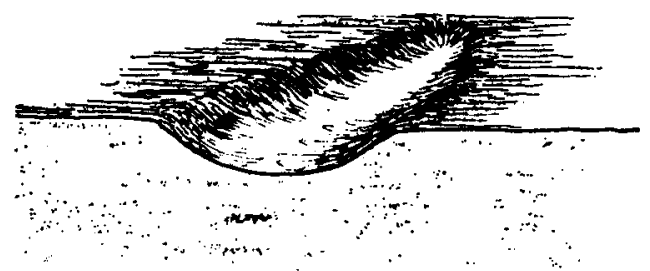

FIG. 3. Diagrammatic sketch of a secondary crater of Eratosthenian age. (Eratosthenian secondary craters generally have no observable raised rims or internal cusps. Based on telescopic observations of $M . H$. Carr.)

rays. Around the ray craters, the secondaries occur within the rays and within the bright halo surrounding the ray crater. Secondary craters associated with primary ray craters, which are referred to the Copernican system of Shoemaker and Hackman (2), generally have raised rims and are composite (Fig. 2). In the swarms of secondaries around rayless primaries, the secondary craters generally have no rims and are long shallow trenches of simple form (Fig. 3). Secondary craters on the maria associated with rayless primaries are referred to the Eratosthenian system 


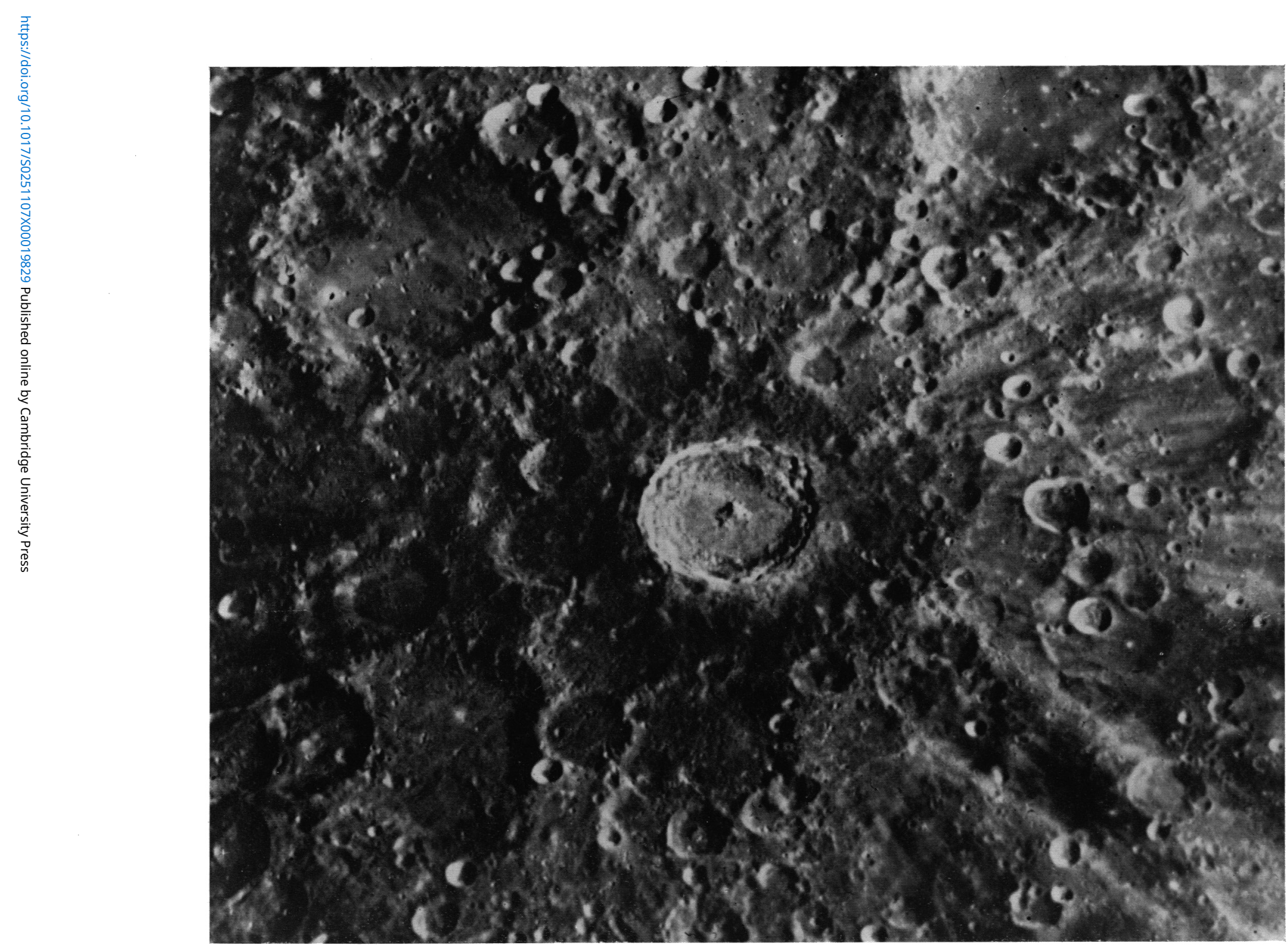

Fig. I. Telescopic photograph of Tycho showing part of its associated swarm of secondary craters. (The secondary craters appear as very small, closely spaced craters, many of which have diameters just above the limit of resolution and are scattered over much larger older craters surrounding Tycho. The diameter of Tycho is $88 \mathrm{~km}$. Photograph from Lick Observatory.) 
of Shoemaker and Hackman (2). Both Copernican and Eratosthenian secondaries are represented in the Ranger VII photographs.

\section{Primary craters}

Primary craters are well represented in the Ranger VII photographs. Their size ranges from that of Bullialdus, $62 \mathrm{~km}$ in diameter, and Darney, $16 \mathrm{~km}$ in diameter-down to $2 \mathrm{~m}$ in diameter, the size of the smallest identifiable primary craters shown in the last photographs obtained from the $P$ cameras. The shape of primarv craters smaller than $7 \mathrm{~km}$ in diameter is essentially the same down to the smallest criter obs red. On all photographs obtained from Ranger VII, from the smallest to the largest scale, the primary craters occupy a very small fraction of the mare surface, typically less than I per cent. At all scales, they appear to be randomly scattered over the field. Over the range of size from $30 \mathrm{~m}$ diameter to the largest primaries photographed, some primary craters are surrounded by bright halos or rays, and some are not (Figs. 4, 5). Discrete bright halos are associated exclusively with primary craters, but no demonstrable variations in albedo have been found around craters smaller than $30 \mathrm{~m}$ in diameter.

\section{Secondary craters}

Secondary craters are abundantly represented in the Ranger VII photographs. In Mare Cognitum, most of them may be identified with three major secondary crater swarms. Most of the secondary craters in the highest-resolution photographs are in a ray belonging to the Tycho system. Only relatively large secondary craters of Copernicus are resolved in the Ranger VII photographs, as Copernicus rays are not present in the highest-resolution pictures. These large secondary craters of Copernicus are best portrayed near the northern margins of A-camera photographs ${ }_{5} 55$ to ${ }_{5} 58$. The third major swarm of secondary craters is associated with the Eratosthenian primary crater Bullialdus, and the differences in form between the larger Copernican and Eratosthenian secondaries are well illustrated in the A-camera photographs.

The swarm of secondary craters within the Tycho ray shown in the photographs near the end of the A-camera sequence (Fig. 6) exhibit details of form and spacing of secondary craters too small to be seen through the telescope. Most readily identifiable secondary craters in this ray range from 200 to about $400 \mathrm{~m}$ across and from about $200 \mathrm{~m}$ to $1 \mathrm{~km}$ in length. Most of the more elongate craters are composed of two, and in some cases three, craters merged together. Craters of this form are closely spaced, forming a rough crescent-shaped pattern opening to the northwest (astronautical coordinates). The convex boundary of the crescent is the approximate margin of the ray, and the largest secondary craters tend to occur along the southern part of the crescent, which is the part nearest Tycho. Along the northern arm of the crescent, the secondary craters are smaller and shallower in proportion to their width, and the rims are distinctly more rounded.

In the southern or proximal part of the crescent-shaped secondary crater cluster are a number of circular, relatively deep craters ranging in diameter from about 400 to $900 \mathrm{~m}$. Except for the lack of well developed rims, some of these circular craters could be mistaken for primary craters, were they not clearly members of the swarm. In another small Tycho ray northwest of the crescent-shaped cluster, all of the largest craters, which form a loose cluster on the end of the ray nearest Tycho, are circular in form. Because they form a cluster and occur within the ray, it is inferred that these also must be secondary craters. It appears that the more open the cluster, the more the secondaries tend to be circular.

The proportion of circular to elongate secondaries is somewhat higher in the rays of Tycho shown in the highest-resolution A-camera photographs than in the typical swarms of secondaries observed through the telescope. It appears that, in a given secondary swarm, the smaller and more widely spaced the craters, the more they tend to be individual and circular rather than composite and elongate. 


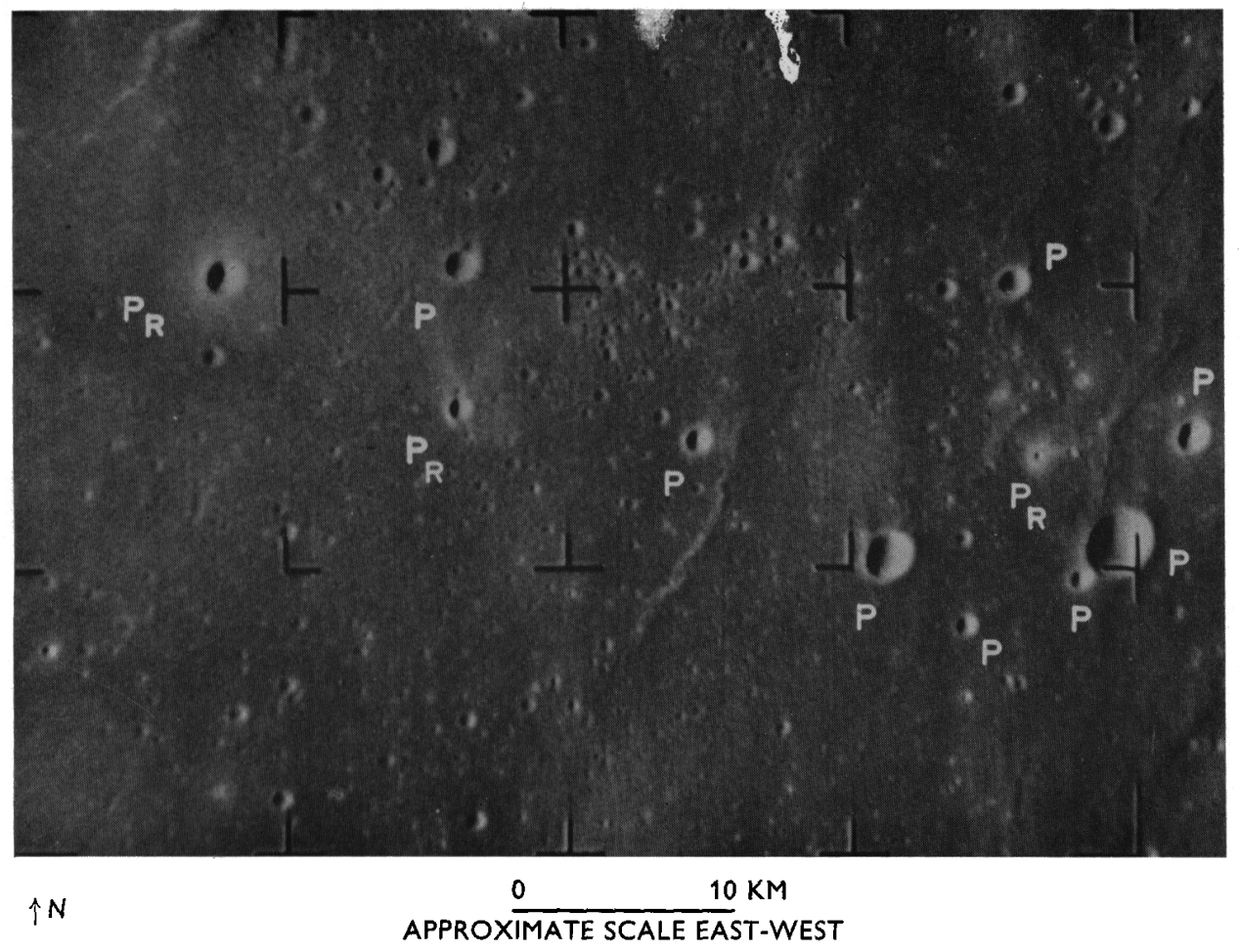

FIg. 4. Part of Camera A photograph 189 showing group of primary craters of intermediate size. (Primary craters without rays are designated $P$, and primary craters with rays are designated $P_{R}$.) 


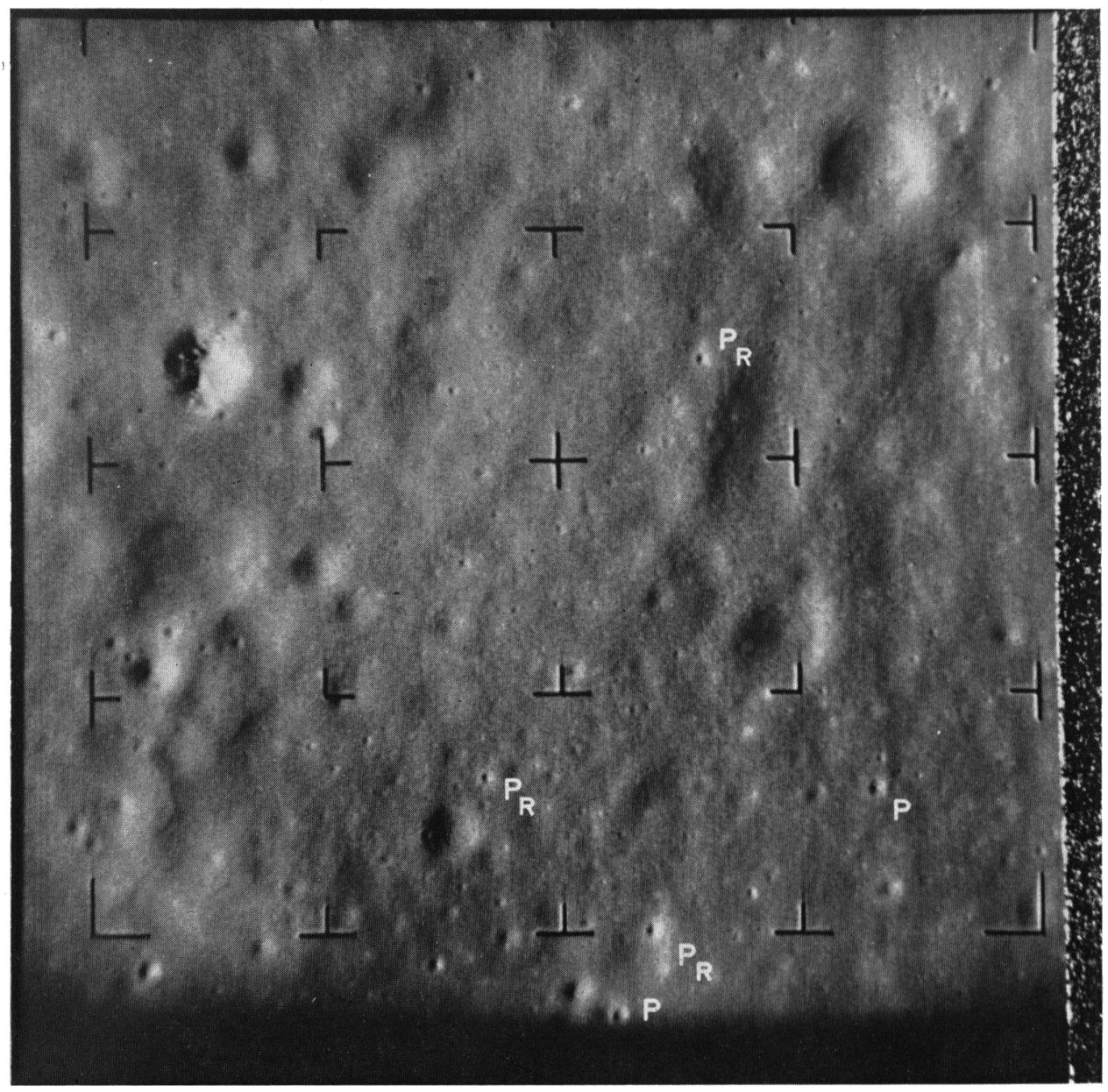

$\uparrow N$

0

$1 \mathrm{KM}$

APPROXIMATE SCALE EAST-WEST

FIG. 5. Camera A photograph 199 showing identifiable primary craters. (Primary craters without rays are designated $\mathbf{P}$, and primary craters with rays are designated $P_{R}$. The smallest ray craters identified are about $30 \mathrm{~m}$ in diameter and are the smallest ray craters so far identified on the Moon.) 


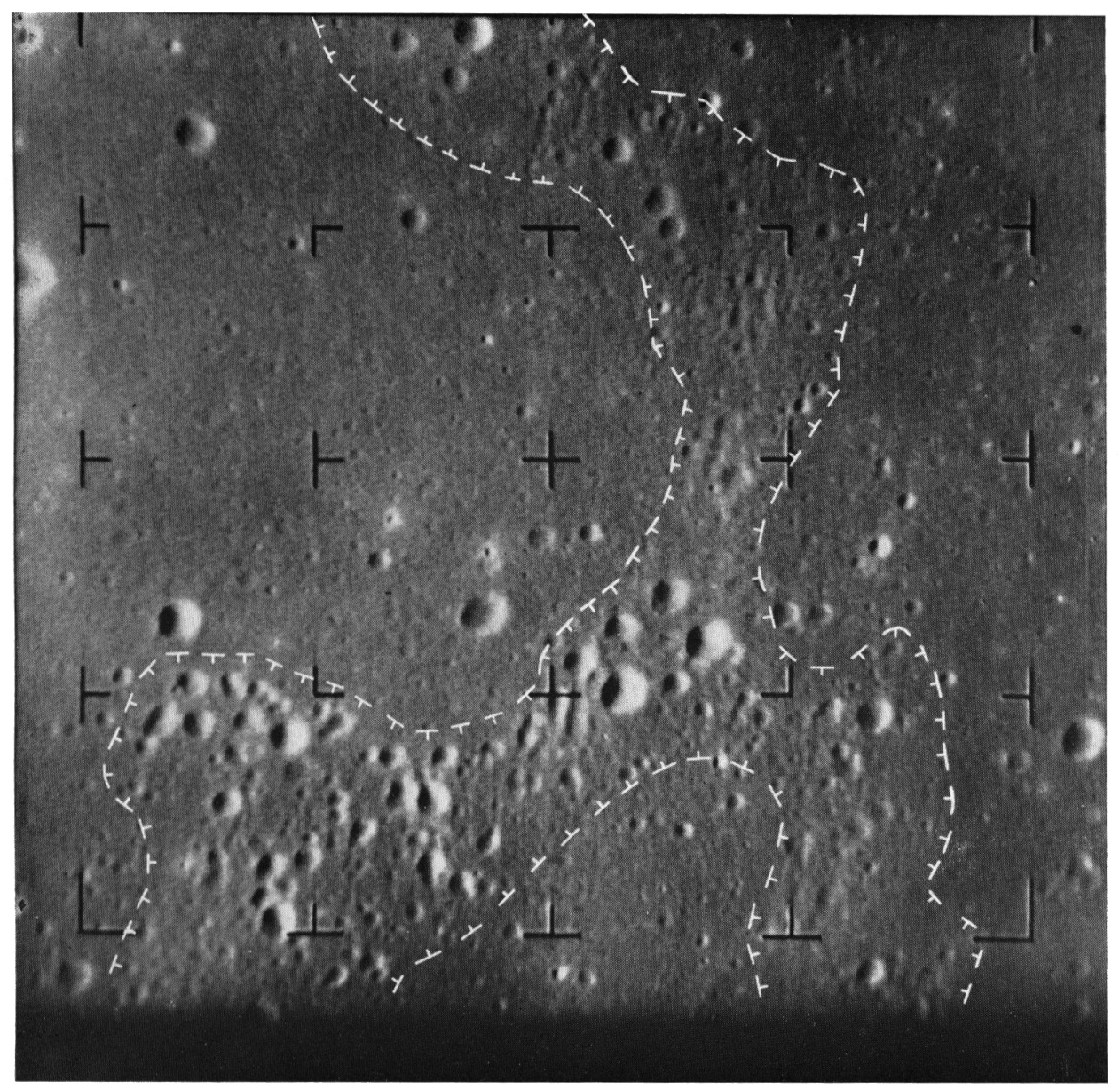

$\uparrow N$

0

$10 \mathrm{KM}$

APPROXIMATE SCALE EAST-WEST

FIg. 6. Camera A photograph 196 showing approximate boundaries of Tycho ray and distribution of secondary craters within the ray. (Dashed lines with tick marks are ray boundaries; tick marks are on ray. Note the abundance of elongate, composite craters in the ray. Nearly all of the elongate craters and most of the circular craters in the ray are interpreted as secondary craters of 'Tycho.) 
Large Eratosthenian secondary craters, most of which are probably related to Bullialdus, are widely scattered over the southern part of Mare Cognitum. Crossing the southern margin of the mare, a row or band of secondary craters may be traced north from Bullialdus (Fig. 7). Near the north end of this row is a very prominent elongate crater over $3 \mathrm{~km}$ long and about I km in maximum width (Fig. 8). It has no discernible rim. The edges of the crater are rounded, and it is much shallower than primaries of $\mathrm{I} \mathrm{km}$ diameter. This crater has a vague internal structure and appears to be composed of about four barely recognizable smaller craters strung end to end. Three closely similar composite secondary craters of about the same size may be seen in this general region of the mare. The one which lies closest to the Ranger impact point is shown with highest resolution in photographs $\mathrm{A}$ I9I, I92, and 193 . Between the rays, in this same general region, are a large number of smaller, less well defined secondary craters, most of which are also probably a part of the Bullialdus swarm. They can be distinguished best in photographs A 182-I86. In the northwest corner of photographs A I86-I88 (Fig. 8) is a series of extremely shallow and very elongate faintly marked features which may belong to an unidentified Eratosthenian secondary swarm, possibly older than that of Bullialdus.

Elongate small secondaries can be recognized in the Ranger VII photographs over the range of length from $3 \mathrm{~km}$ down to $\mathrm{I} \mathrm{m}$. At least two sets of very small secondaries appear to be recognizable in the last part of the sequence of photographs obtained by the $\mathrm{P}$ cameras, one set with long axes tending north-northwest and the other set north-northeast. These very small secondary craters are probably related to two or more near-by primary craters in Mare Cognitum, possibly two primaries about $\mathrm{I} \mathrm{km}$ across or smaller with conspicuous bright halos that lie south of the Ranger impact point (Fig. 4).

\section{Craters less than $300 \mathrm{~m}$ in diameter}

Nearly all craters shown on the Ranger VII photographs in Mare Cognitum that are greater than $I \mathrm{~km}$ across can be classified as primary or as secondary craters. The majority of them are primary. In the diameter range from $300 \mathrm{~km}$ to $\mathrm{I} \mathrm{km}$, most of the craters can also be classified as primary or as secondary, but craters of this size are predominantly secondary craters. Beginning with craters with a diameter of about $500 \mathrm{~m}$ and extending to smaller sizes, a number of craters are observed in the Ranger photographs that are not clearly assignable either to the primary or to the secondary class. These craters are circular but have low rounded rims, and are shallower than typical primary craters (Fig. 9). In the areas between the rays, these shallow circular craters do not clearly belong to any recognizable secondary crater swarm. They may be degraded primary craters or isolated, round, degraded secondary craters. Among craters less than $300 \mathrm{~m}$ in diameter, the crater population is dominated by this third indefinite type.

All gradations in form of circular craters may be observed among craters less than $300 \mathrm{~m}$ across. They range from steep-walled primaries to craters with no discernible raised rim and with such gentle interior slopes that the craters are barely detectable in the photographs. For each size class from 2 to $300 \mathrm{~m}$ diameter, a complete sequence of crater forms with varying depth and slope of wall may be found between the primary and the shallowest, barely detectable craters. The edges of all the shallow craters are invariably rounded and, in fact, are generally so smooth in the shallowest craters as to defy precise location.

Many very shallow round-edged elongate or irregular craters less than $300 \mathrm{~m}$ in diameter are also represented in the high-resolution photographs (Fig. 9). They occur both in and between the major rays.

\section{Distribution of craters}

The size-frequency distributions in Mare Cognitum of primary and secondary craters greater than $\mathrm{I} \mathrm{km}$ across are close to the average for other maria. The newly observed distributions of small craters represent extensions of three orders of magnitude of crater diameters 


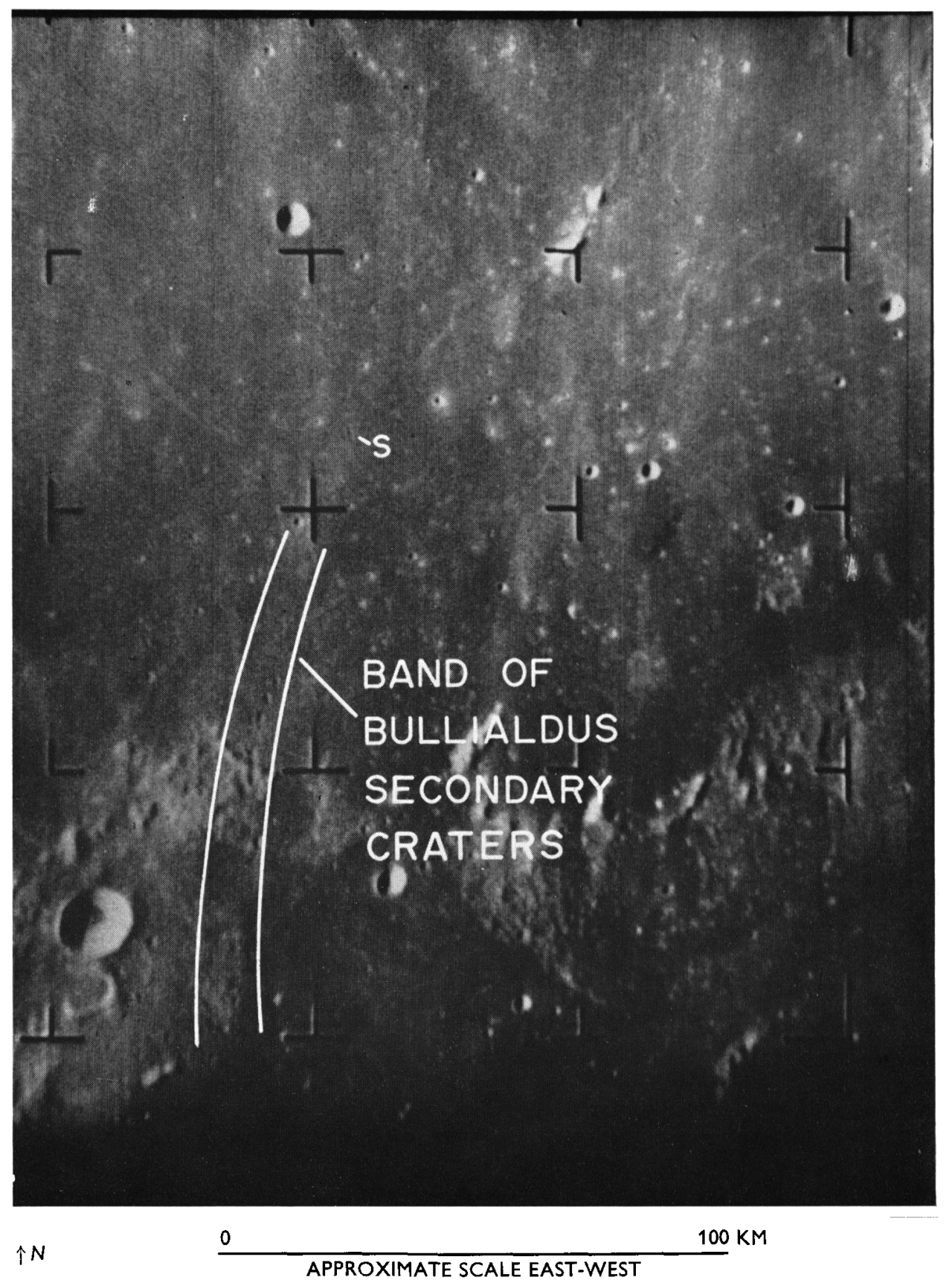

Fig. 7. Part of camera A photograph 56 showing band of Bullialdus secondary craters. (Large Eratosthenian secondary crater beyond band (designated $\mathrm{S}$ ) probably also belongs to the Bullialdus secondary crater swarm.) 


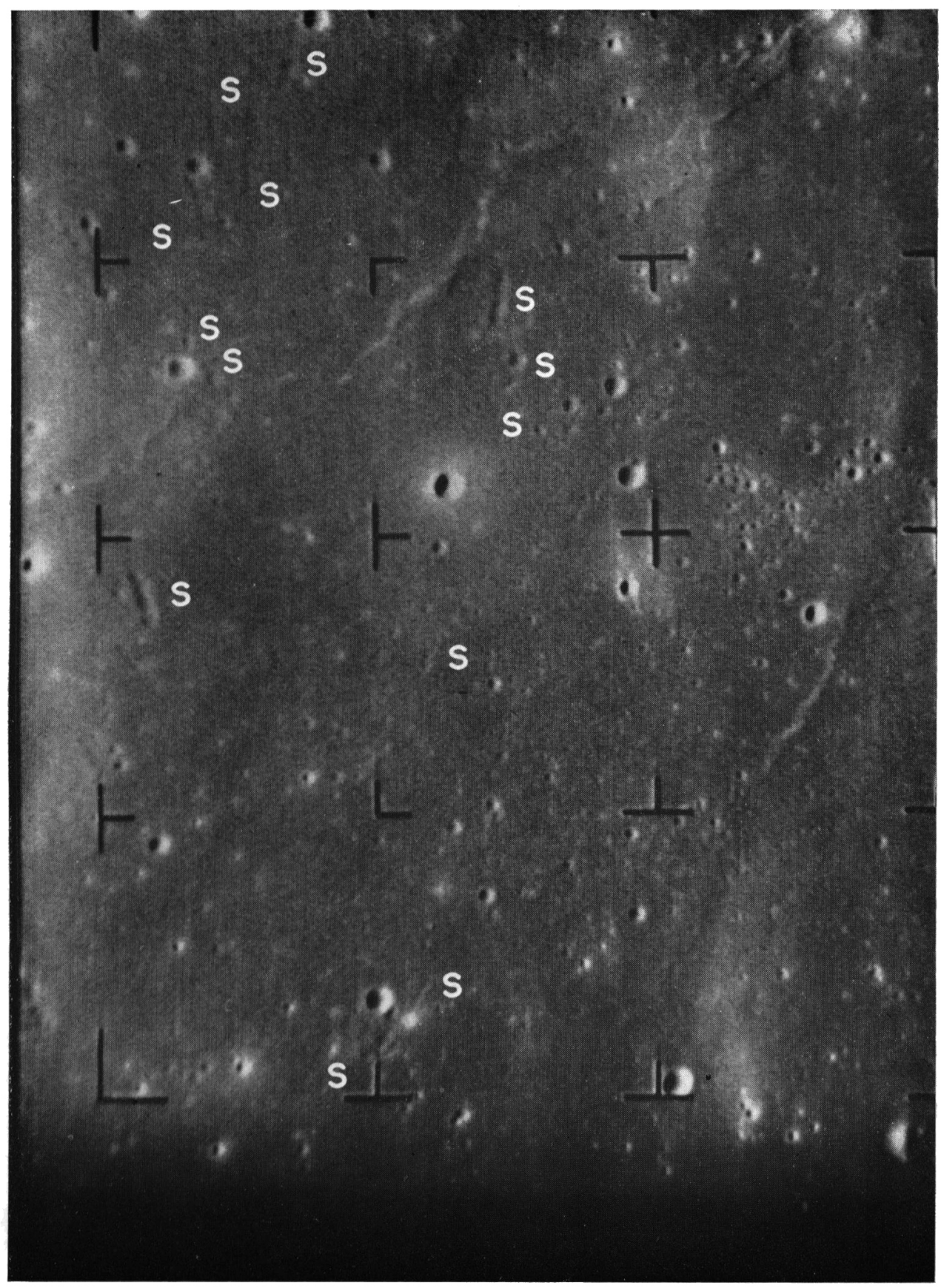

$\uparrow N$

\section{APPROXIMATE SCALE EAST-WEST}

FIg. 8. Part of camera A photograph I 86 showing distribution of large Eratosthenian secondary craters (designated $\mathrm{S}$ ). 


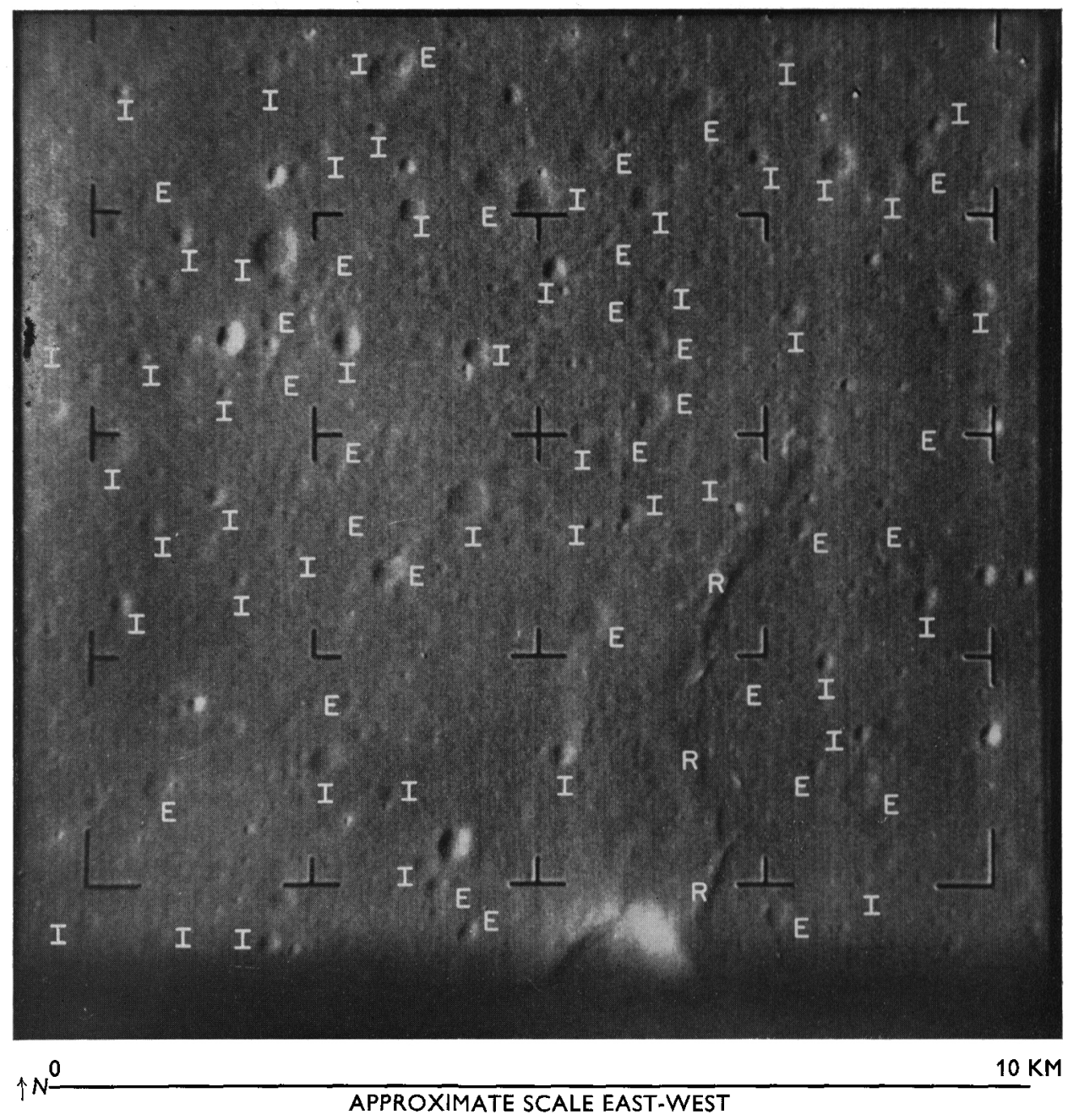

FIG. 9. Camera B photograph 197 showing distribution of shallow circular craters with low rounded rims (designated I) of indefinite classification, and elongate and irregular craters (designated E). (Only the largest craters in these two classes are marked. A prominent ridge in the lower right part of the photograph is designated R. Note the presence of sharply defined branches or spurs on the ridge.) 
below the previously known size distributions for larger craters on the maria. It is important to distinguish between the distribution of the craters in the major ray systems and the distribution in the areas between the rays.

\section{Ray areas}

With increasing resolution, the observed ray areas in Mare Cognitum begin to fill up very rapidly with craters less than $\mathrm{I} \mathrm{km}$ across, but the crater distributions within the rays is irregular. Some parts of the crescent-shaped ray shown in the last A-camera photographs are more than 50 per cent occupied by secondary craters $300 \mathrm{~m}$ across and larger. In the northern part of the same ray, however, only 20 per cent of the ray is occupied by craters of that size. Craters larger than $300 \mathrm{~m}$ are similarly sparse in the ray to the northwest of the crescent-shaped ray. For craters much smaller than $300 \mathrm{~m}$ in diameter, data are available only for the crescent-shaped ray; all of the highest-resolution photographs are in the northern branch of this ray, where the abundance of larger craters is lower than average for the entire crescent.

The last A-camera frame, I99 (Fig. 5), illustrates what appears to be fairly representative of the northern part of the crescent-shaped ray. Craters from ro to $300 \mathrm{~m}$ in diameter can be detected in this photograph. Approximately 50 per cent of the field is covered by craters. By far the greatest number of these belong to the indefinite class of shallow craters; many are extremely shallow depressions. Craters from 10 to $50 \mathrm{~m}$ in diameter cover 25 to 30 per cent of the field and are scattered more or less uniformly over the larger craters and the areas between the larger craters. Many of the smallest craters are difficult to distinguish on the photographs reproduced in the A-camera Atlas, but their occurrence and distribution can be seen on enhanced photographs from which some of the coherent noise has been removed.

The last photographs obtained from the $\mathrm{P}$ cameras, which appear to be fairly representative samples of the ray area covered in A 199 , show that between 25 and 50 per cent of the field is occupied by craters from $\mathrm{I}$ to $\mathrm{IO} \mathrm{m}$ in diameter (Fig. IO). Again, smaller craters are scattered over the larger ones.

The cumulative size-frequency distribution of craters in the ray area sampled by the Ranger photographs is illustrated in Fig. I I, which shows the distribution for all types of craters, from the largest observed in Mare Cognitum down to those $1 \mathrm{~m}$ in diameter. For craters larger than I km across, the curve represents the entire mare, but for smaller craters the data are necessarily restricted to areas sampled by the Ranger photographs, and only a very minute area is sampled to obtain the estimated frequency of the smallest craters.

\section{Areas between rays}

Between the rays, the craters are more evenly distributed than in the rays. The spatial density of craters less than $\mathrm{I} \mathrm{km}$ in diameter increases more slowly with increasing resolution than in the rays. In the sampled areas, covered chiefly by the B-camera photographs, craters greater than $300 \mathrm{~m}$ across are fairly widely spaced, occupying about 5 per cent of the total field. With further increase in resolution, the field fills rapidly with craters less than $300 \mathrm{~m}$ in diameter. Approximately 20 per cent of the field is covered with craters ranging from 50 to $300 \mathrm{~m}$ in diameter in the areas for which data are available (from highest-resolution B-camera photographs). Again, the large majority of the craters are of the indefinite shallow type, most of them very shallow with gently rounded rims. The distribution of craters much smaller than about $50 \mathrm{~m}$ in diameter in the areas between the rays cannot be obtained from the Ranger VII photographs because most of the pictures showing smaller craters are within the crescent-shaped ray. Thus, the range of crater sizes, where small craters would be expected to be found abundantly scattered over larger craters, lies beyond the limits of best resolution for the Ranger coverage of the areas between the rays. 


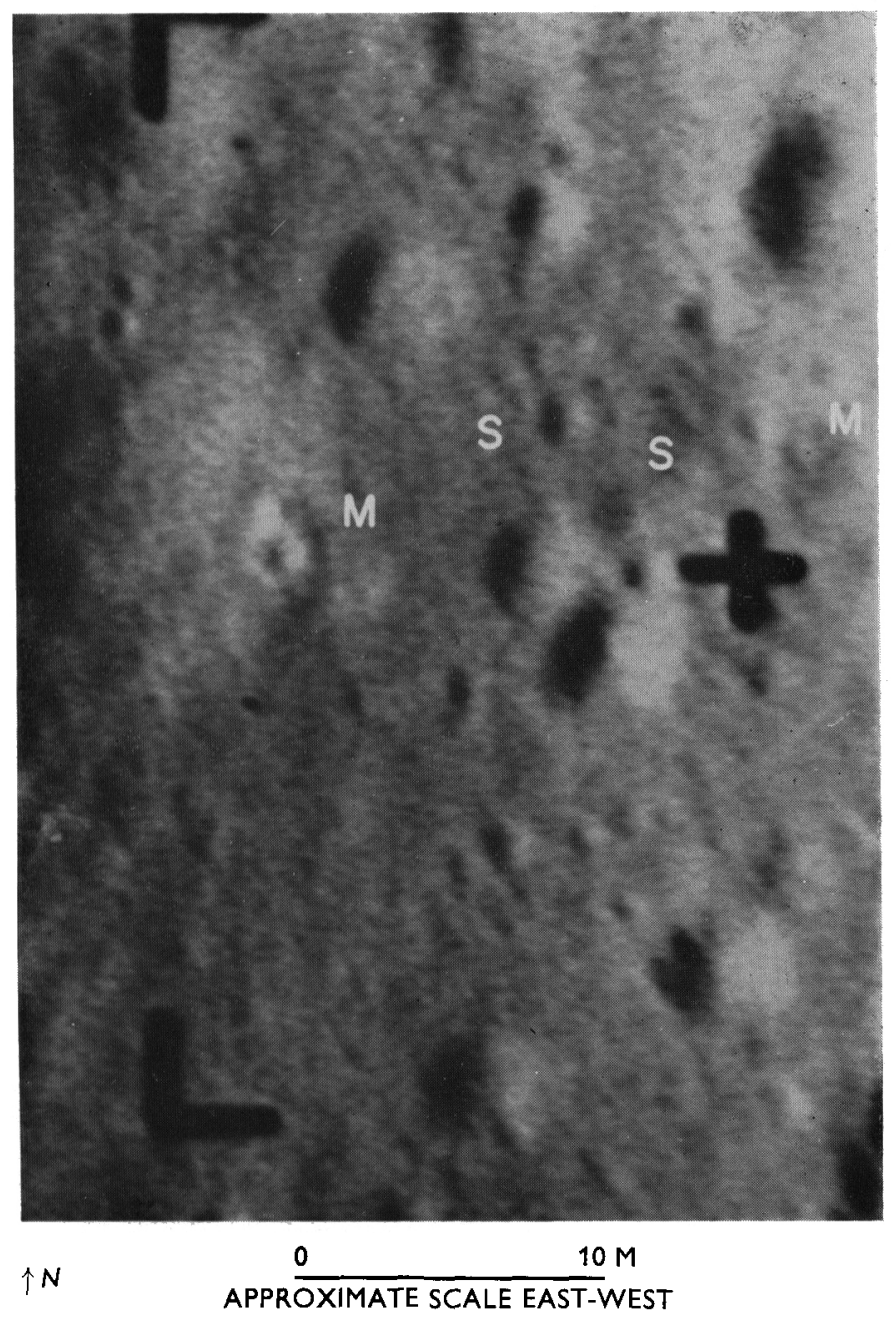

Fig. 1o. Last $P_{3}$ photograph showing small secondary craters (designated $S$ ) and mounds with summit craters (designated $M$ ). (The length of the secondary craters is exaggerated by image motion, but the secondary craters are also elongate in the general direction of motion of the image as shown by the presence of small circular craters in the same part of the field.) 


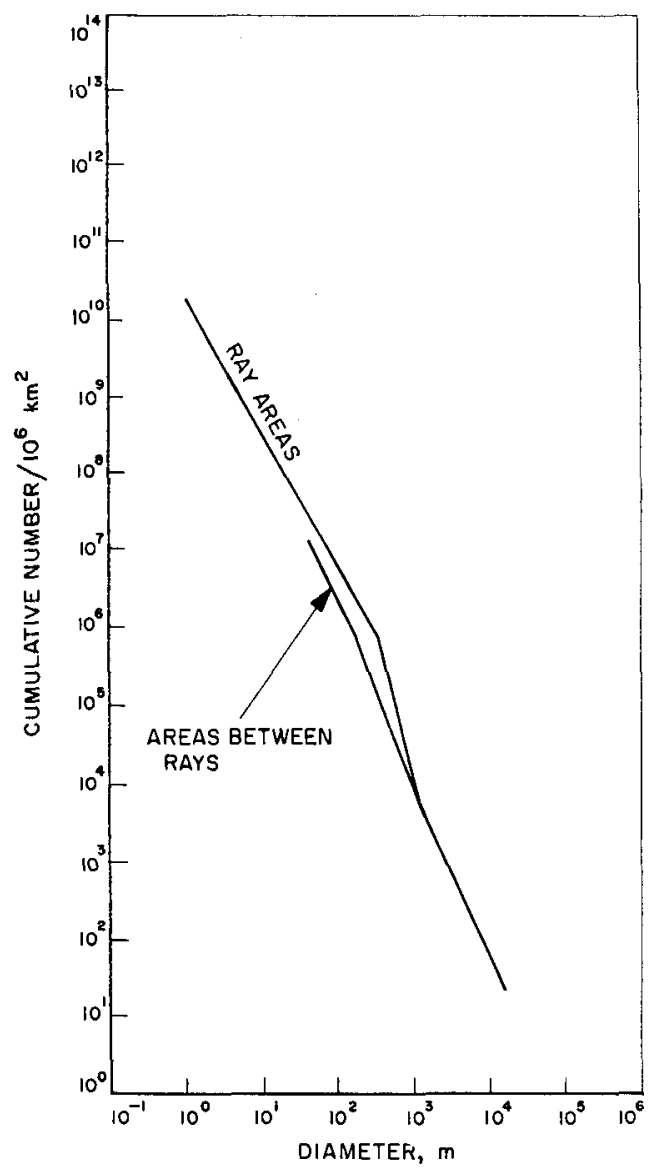

FIG. II. Cumulative size-frequency distribution of craters in Mare Cognitum (based on distribution of craters observed in Ranger VII photographs).

The cumulative size-frequency distribution for all types of craters between the rays is shown as a separate branch of the distribution curve in Fig. II.

\section{Interpretation of observations}

The primary craters on the maria are here interpreted as having been formed by impact of meteoroids and larger interplanetary objects such as asteroids and comet nuclei. According to this interpretation, the observed primary craters were formed by high-velocity solid objects, ranging in diameter from several centimeters to a few kilometers, striking the solid surface of the mare and propagating a shock locally in the mare material. This process has probably continued intermittently since the maria were formed, possibly as long as several billion years.

The secondary craters are interpreted as having been formed by impact of comparatively low-velocity fragments of the Moon ejected from primary craters located both on the maria and on other parts of the lunar surface. (For an explicit account of the interior ballistics of a primary crater and the exterior ballistics of secondary crater-forming fragments, see (3), pp. 329-340.) 


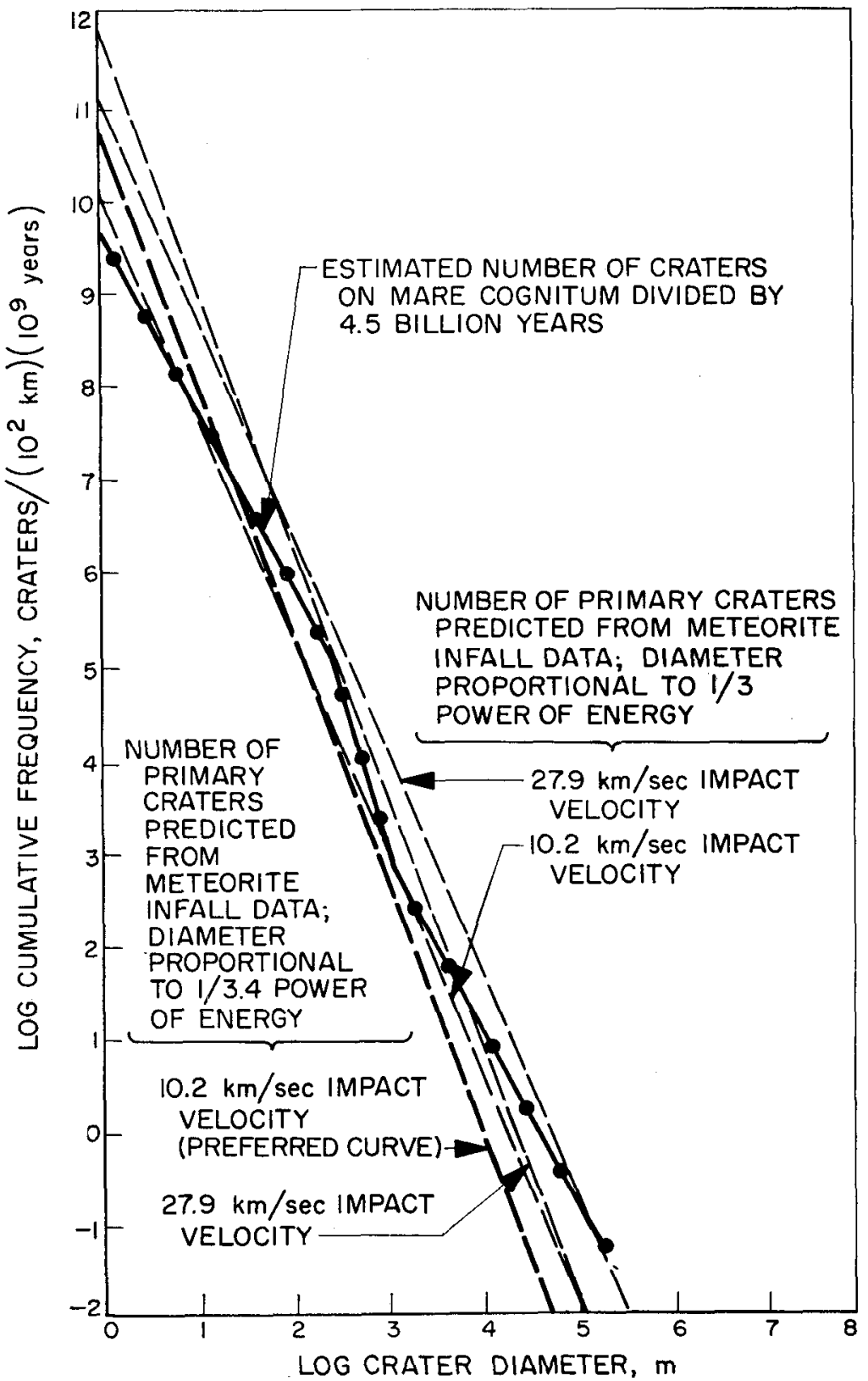

FIG. I2. Cumulative size-frequency distribution of craters in Mare Cognitum compared with cumulative size-frequency distribution predicted for primary craters on the basis of meteorite infall data. (Sizefrequency distribution of craters in Mare Cognitum estimated from Ranger VII photographs is an average for ray areas and areas between rays.) 
The rays on Mare Cognitum, under this interpretation, consist primarily of mare material ejected from the secondary craters but contain a small admixture of material derived from the more distant primary crater with which the rays are associated.

\section{Primary crater distribution}

The expected or predicted size-frequency distribution of primary craters on the lunar maria, obtained by extrapolating the estimated size-frequency distribution of meteorites falling on the Earth to very large sizes and by extrapolating the present estimated rate of infall backward in time, is illustrated in Fig. $12(4)$. The meteorite infall data used are from (5) and (6); it is necessary to adopt likely impact velocities for the meteorites striking the Moon and to employ empirical scaling laws to derive crater size-frequency distributions. An age of $4.5 \times 10^{9}$ years, the approximate age of the Earth (7), has been arbitrarily assumed for the maria in order to compare predicted primary crater distributions with the observed crater distribution on Mare Cognitum.

The size-frequency distributions of identifiable primary craters and of the total number of craters observed in the Ranger VII photographs are plotted as separate curves in Fig. 13. The curves join at about I $\mathrm{km}$ crater diameter, as all craters much larger than this observed in the Ranger photographs (in Mare Cognitum) are identifiable primary craters. At $100 \mathrm{~m}$ crater diameter, the total number of craters is an order of magnitude larger than the number of identifiable primary craters, and at a few meters crater diameter, the total number of craters is more than an order of magnitude larger than the number of identifiable primaries. The predicted number of primary craters (preferred curve) is more than two orders of magnitude greater than the observed number at a few meters crater diameter. This difference between predicted and observed numbers of primary craters decreases rapidly with increasing crater size, and the two curves intersect at about $400 \mathrm{~m}$ crater diameter.

\section{Secondary crater distribution}

The rate of formation of secondary craters on the Moon can be estimated from the primary cratering rate if the size distribution of secondary craters formed by individual primary craters is known. A predicted size distribution of secondary craters on the maria can be derived from the observed distribution of large primary craters, moreover, without any assumptions about the age of the maria or about the cratering rate. To do this, we require empirical data on the size-frequency distribution of secondary craters produced by primary craters of different sizes. Around very large craters on the Moon, part of the size distribution of secondary craters can be observed directly.

If it is assumed that the number and size distribution of secondary craters observed in the crescent-shaped cluster in the highest-resolution Ranger VII A-camera photographs is representative of the number and size distribution of small secondary craters in the rest of the Tycho ray system, then we may estimate the cumulative size-frequency distribution of the Tycho secondary craters from the largest secondaries formed around Tycho down to $200 \mathrm{~m}$ in diameter. It is found, on this basis, that the cumulative number of secondary craters formed around a single primary is very closely a simple power function of the diameters up to a cumulative number of 100000 craters. The exponent of the function that best fits the estimated size distribution is slightly greater than -4 .

An estimate of the number of secondary craters that have been formed on the maria may be made by integrating the number of secondary craters expected for each primary. It will be assumed that 100000 secondaries are formed by each primary. For this estimate, an age of $4.5 \times 10^{9}$ years is adopted for the maria. The primary crater distribution curve adopted in making the estimate has two branches: ( 1 ) the preferred curve for primary craters based on meteorite infall data, which extends from diameters of $\mathrm{m}$ to about $400 \mathrm{~m}$, and (2) the observed 


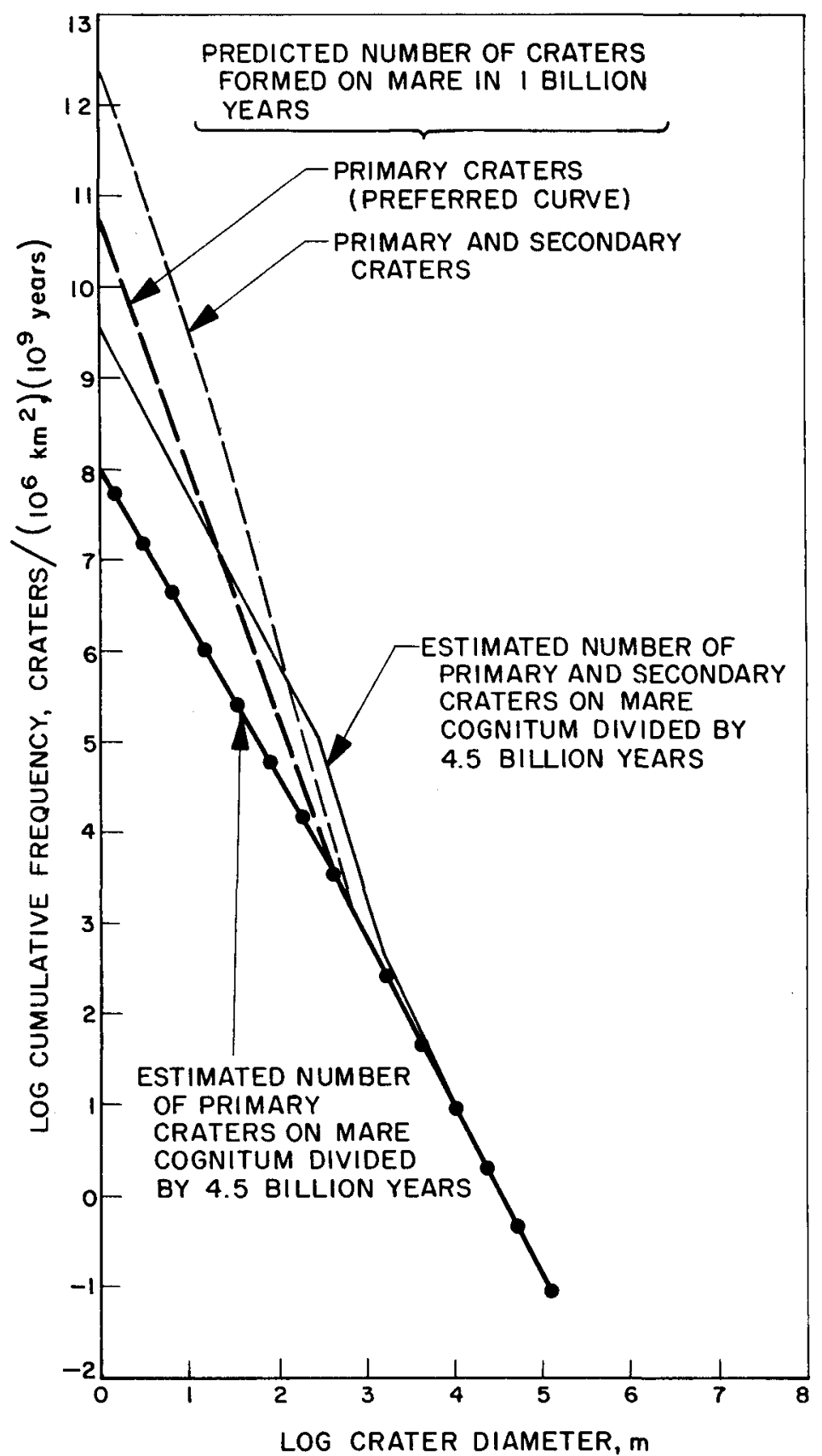

FIG. I3. Cumulative size-frequency distribution of primary craters and of all craters on Mare Cognitum compared with predicted size-frequency distribution of primary craters and of all craters. 
crater frequency distribution of the lunar maria for diameters above $400 \mathrm{~m}$. The predicted cumulative number of all craters larger than $\mathrm{I} \mathrm{m}$ in diameter is about $5^{\circ}$ times greater than the predicted cumulative number of primary craters of that size.

The predicted cumulative number of all craters $\mathrm{r} \mathrm{m}$ in diameter and larger (improved estimate) is more than two orders of magnitude greater than the estimated cumulative number of all craters based on the Ranger VII photographs. At diameters of a few meters, the ratio of the cumulative number predicted to the number observed is about the same for all craters (primary and secondary combined) as it is for the primary craters. As in the case of the primaries, this ratio decreases rapidly with increasing crater size, and the predicted and observed curves cross at a diameter between 100 and $200 \mathrm{~m}$. For areas between the rays, the predicted and observed cumulative curves for all craters join at about $300 \mathrm{~m}$.

\section{Effects of interaction of small craters}

The predicted number of small craters, both primary and secondary, is so great that craters are expected to have been formed everywhere on the lunar maria. On the basis of the improved prediction for the cumulative number of all craters larger than $1 \mathrm{~m}$ across, the mare surface would have been cratered repeatedly at any one place. It is impossible, in other words, to observe the predicted number of craters larger than I $\mathrm{m}$ across because their total area is more than Io times as great as the area of the mare surface. The effect of repeated cratering is to reduce the total number of craters that are observable.

On a surface which is continuously being formed and reformed, the shapes of craters are modified by two processes. The first process is the actual destruction or removal of a crater by the formation of a new crater the same size or larger. In the second process, a crater is gradually covered over by fragments and peppered with smaller craters in the time intervals between larger cratering events. The latter process, if it continues sufficiently long, will so modify the shape of the crater that it is no longer recognizable. With a given flux of impacting objects, the distribution of observed craters below some limiting size will tend toward a steady size-frequency distribution. Within the size range in which the distribution remains steady, new craters are formed as fast as old ones disappear from the combined effects of the two crater-modification processes. There will be a steady number of craters of any given size, no matter how long the cratering continues, and craters of a given size will exhibit a complete range of shapes from fresh unmodified forms to forms so modified that the crater is barely discernible. Above this limiting size, craters may undergo considerable modification in shape, but those formed do not disappear. With a given flux and size distribution of impacting objects, the limiting size of the steady crater size distribution gradually increases with time.

The predicted curves in Fig. 13 represent the numbers of craters expected to have been formed in each million square kilometers of the mare surface per billion years, whereas the curves based on the Ranger VII data represent the observed distribution of craters per million square kilometers divided by 4.5 to give the equivalent rate of cratering per $10^{9}$ years. If the predicted curves for the number of craters formed are valid, they should join the observed curves, both for primary craters and for primary and secondary craters combined, at the limiting size for steady frequency distribution. This occurs at approximately $400 \mathrm{~m}$ for the primaries and at approximately $300 \mathrm{~m}$ for all craters in the areas between the rays. Inasmuch as the locations of the points at which the observed and predicted curves join are very sensitive to small variations in the predicted curves, this difference is not judged to be significant. In the ray areas, the observed number of all craters is actually above the predicted curve between $150 \mathrm{~m}$ and about $\mathrm{I} \mathrm{km}$ diameter because of the local concentration of Tycho secondary craters in the rays, but is below the predicted curve for diameters less than $150 \mathrm{~m}$. Except for this local concentration of Tycho secondaries, the difference between the observed and the predicted curves may be interpreted as representing the numbers of craters lost by the effects of 
crater interaction. At diameters of a few meters, several hundred times as many craters have been formed and subsequently destroyed as are now present on the mare surface. The ratio of craters formed on the maria to those now present is essentially the same for primary and secondary craters.

\section{REFERENCES}

I. Kuiper, G. P. 'The Exploration of the Moon', Vistas in Astronautics. Ed. by Alperin, Morton and Gregory, Pergamon Press, New York, Vol. 2, pp. 273-313, I959.

2. Shoemaker, E. M., Hackman, R. J. 'Stratigraphic Basis for a Lunar 'Time Scale', The Moon-IAU Symposium no. 14. Ed. by Z. Kopal and Z. K. Michailov, Academic Press, London, pp. 289-300, I962.

3. Shoemaker, E. M. 'Interpretation of Lunar Craters', Physics and Astronomy of the Moon. Ed. by Z. Kopal, Academic Press, London, pp. 283-359, 1962.

4. Shoemaker, E. M., Hackman, R. J., Eggleton, R. E. 'Interplanetary Correlation of Geologic Time', Advances in the Astronautical Sciences, Plenum Press, New York, vol. 8, pp. $70-89,1963$.

5. Brown, H. 'The Density and Mass Distribution of Meteoritic Bodies in the Neighborhood of the Earth's Orbit-Addendum', F. geophys. Res., 66, I316, I961.

6. Patterson, C. C., Tilton, G. R., Inghram, M. G. 'Age of the Earth', Science, r21, 69, 1955.

7. Whipple, F. L., Hughes, R. F. 'On the Velocities and Orbits of Meteors, Fireballs and Meteorites', $\mathcal{F}$. atmos. and terr. Phys., Suppl. 2, 149, 1955. 